\title{
What Properties of Sodium-Glucose Cotransporter 2 Inhibitors Determine the Improvement in Hemoglobin A1c and Body Weight?
}

\author{
Hidekatsu Yanai $^{\mathrm{a}, \mathrm{b}}$, Mariko Hakoshima ${ }^{\mathrm{a}}$, Hiroki Adachi ${ }^{\mathrm{a}}$
}

\section{To the Editor}

We previously reported that sodium-glucose cotransporter 2 inhibitors (SGLT2i) have been proved to be significantly associated with improvement in hemoglobin A1c (HbAlc) and body weight by a relatively large number of studies [1]. We also demonstrated that SGLT2i significantly reduced HbA1c and body weight and improved liver function [2]. Further, I experienced a patient whose $\mathrm{HbA} 1 \mathrm{c}$ remarkably changed by the switching of SGLT2i, and proposed that the change in HbA1c by the SGLT2i switching may be due to various degrees of selectivity toward SGLT2 which is highly expressed in kidney versus selectivity toward SGLT1 which is highly distributed in intestine [3]. Therefore, we studied an influence of the estimated glomerular filtration rate (eGFR) on the improvement in metabolic parameters by SGLT2i, and we found that eGFR has an influence on the improvement in $\mathrm{HbA} 1 \mathrm{c}$ and liver function; however, eGFR did not show an influence on the change in body weight [4].

However, our previous studies did not answer the question: what properties of SGLT2i determine the improvement in $\mathrm{HbA} 1 \mathrm{c}$ and body weight. Therefore, we studied the correlation of pharmacokinetic properties of SGLT2i with the improvement in $\mathrm{HbAlc}$ and body weight. Daily standard dose, maximum plasma concentration (MC), SGLT2 inhibitory concentration $50 \%$ value (IC50) and SGLT2 selectivity which is the ratio of IC50 of each SGLT2i against SGLT1 to its IC50 against SGLT2 were shown in Figure 1 [5, 6]. Data about MC and IC50 were obtained from the article by Nishiyama et al [5], and data about SGLT2 selectivity were obtained from the article by Suzuki et al [6]. We divided SGLT2i into high-dose, medium-dose and low-dose groups, and found that high-dose group showed high MC and low-potent, and medium-dose

Manuscript accepted for publication March 14, 2017

a Department of Internal Medicine, National Center for Global Health and Medicine Kohnodai Hospital, Chiba, Japan

${ }^{\mathrm{b}}$ Corresponding Author: Hidekatsu Yanai, Department of Internal Medicine, National Center for Global Health and Medicine Kohnodai Hospital, 1-7-1 Kohnodai, Ichikawa, Chiba 272-0034, Japan.

Email: dyanai@hospk.ncgm.go.jp

doi: https://doi.org/10.14740/jocmr3004w group showed medium MC and medium-potent and low-dose group showed low MC and high-potent.

Changes in $\mathrm{HbAl}$ c and body weight after the start of the treatment by each SGLT2i in patients with type 2 diabetes were shown in Table 1. These data were obtained from the interview form of each SGLT2i produced in Japan. We here showed the changes in $\mathrm{HbAlc}$ in patients with moderate renal insufficiency, because SGLT2 is abundantly distributed in the proximal tubules of kidney and renal insufficiency may influence efficacy of SGLT2i.

Correlations between changes in $\mathrm{HbA} 1 \mathrm{c}$ and body weight by SGLT2i and pharmacokinetic parameters of SGLT2i were shown in Table 2. High IC50 means low potency, therefore, we expressed "potency" by dividing the highest IC50 (ipragliflozin; 7.4) by IC50 of each SGLT2i. IC50 did not show any correlation with all parameters; however, potency tended to be correlated with $\mathrm{HbA} 1 \mathrm{c}$ reduction after 24 weeks. Data about the area under the blood concentration time curve (AUC) were also obtained from the article by Nishiyama et al [5]. In this analysis of correlation, the changes in $\mathrm{HbAl} \mathrm{c}$ in patients with moderate renal insufficiency by dapagliflozin and empagliflozin were converted by the following formula: $((\mathrm{n} \times \Delta \mathrm{HbA} 1 \mathrm{c}$ in $30 \leq \mathrm{eGFR}<45)+(\mathrm{n} \times \Delta \mathrm{HbA} 1 \mathrm{c}$ in $45 \leq \mathrm{eGFR}<60)) /((\mathrm{n}$ in $30 \leq \mathrm{eGFR}<45)+(\mathrm{n}$ in $45 \leq \mathrm{eGFR}<60))$, which was used as representative data for dapagliflozin and empagliflozin.

$\mathrm{MC}, \mathrm{MC} \times$ potency and AUC were significantly correlated with reduction of $\mathrm{HbA} 1 \mathrm{c}$ after 12 weeks; however, significant correlations of $\mathrm{MC}$ and $\mathrm{AUC}$ with reduction of $\mathrm{HbAlc}$ after 24 weeks were not obtained. However, MC $\times$ potency was still significantly correlated with reduction of $\mathrm{HbAlc}$ after 24 weeks, and also showed the highest correlation coefficient with reduction of $\mathrm{HbA} 1 \mathrm{c}$ after 12 weeks, suggesting that $\mathrm{MC}$ $\times$ potency is the most crucial determinant of $\mathrm{HbAlc}$ reduction by SGLT2i.

$\mathrm{MC}, \mathrm{AUC}$ and $\mathrm{MC} \times$ potency were not correlated with body weight reduction. Body weight reduction after 12 weeks was significantly correlated with $\mathrm{HbA1c}$ reduction after 12 weeks in patients with renal insufficiency. These results suggest that body weight reduction by SGLT2i cannot be explained by only SGLT2 inhibition. In our previous study using type 2 diabetic patients without renal insufficiency (mean eGFR, 93 $\mathrm{mL} / \mathrm{min} / 1.73 \mathrm{~m}^{2}$ ), there were no significant differences in the changes in body weight between the high eGFR group (mean eGFR, $117 \mathrm{~mL} / \mathrm{min} / 1.73 \mathrm{~m}^{2}$ ) and the low eGFR group (mean 
a Daily standard dose (mg) in Japan

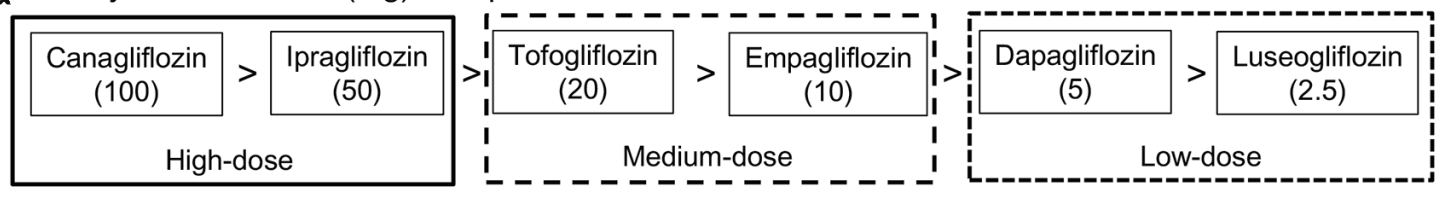

b Maximum plasma concentration $(\mathrm{MC})(\mathrm{ng} / \mathrm{mL})[5]$

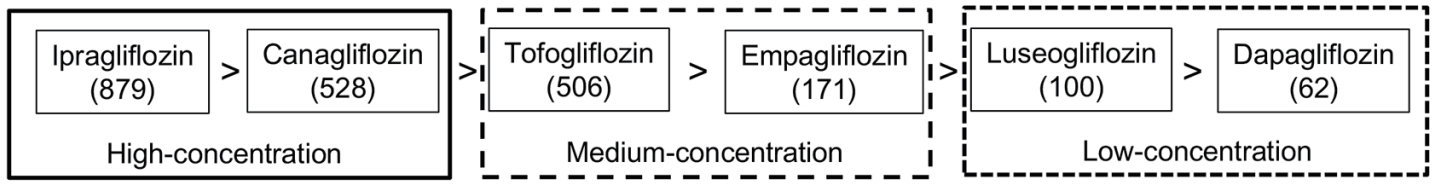

C SGLT2 inhibitory concentration $50 \%$ value (IC50) (nM) [5]

\begin{tabular}{|c|c|c|c|c|c|c|c|c|c|}
\hline $\begin{array}{c}\text { Dapagliflozin } \\
\text { (1.1) }\end{array}$ & $<$ & $\begin{array}{c}\text { Luseogliflozin } \\
\text { (2.3) }\end{array}$ & \begin{tabular}{|c|c}
$<$ & Tofogliflozin \\
& $(2.9)$
\end{tabular} & $<$ & $\begin{array}{c}\text { Empagliflozin } \\
(3.1)\end{array}$ & $1<$ & $\begin{array}{c}\text { Canagliflozin } \\
(4.2)\end{array}$ & $<$ & $\begin{array}{c}\text { Ipragliflozin } \\
(7.4)\end{array}$ \\
\hline High & ר-po & tent & Medi & $a m-r$ & otent & I & \multicolumn{3}{|c|}{ Low-potent } \\
\hline
\end{tabular}

d SGLT2 selectivity [6]

\begin{tabular}{|c|c|c|c|c|c|c|c|c|c|}
\hline $\begin{array}{l}\text { Tofogliflozin } \\
\text { (2900) }\end{array}$ & $>$ & $\begin{array}{l}\text { Luseogliflozin } \\
\qquad(1600)\end{array}$ & $>\begin{array}{c}\text { Empagliflozin } \\
(1100)\end{array}$ & $>$ & $\begin{array}{l}\text { Iplagliflozin } \\
(860)\end{array}$ & $>$ & $\begin{array}{c}\text { Dapagliflozin } \\
(610)\end{array}$ & $>$ & $\begin{array}{c}\text { Canagliflozin } \\
\text { (290) }\end{array}$ \\
\hline
\end{tabular}

Figure 1. Daily standard dose (a), maximum plasma concentration (b), SGLT2 inhibitory concentration $50 \%$ value (c) and SGLT2 selectivity (d) of each SGLT2i. The data in (a) were obtained by the interview form of each SGLT2i produced in Japan, data in (b) and (c) were obtained from the article by Nishiyama et al [5], and data in (d) were obtained from the article by Suzuki et al [6].

eGFR, $72 \mathrm{~mL} / \mathrm{min} / 1.73 \mathrm{~m}^{2}$ ), and the changes in body weight were not correlated with the baseline eGFR value at any points of time [4]. In the present study, body weight reduction after 12 weeks tended to be correlated with low selectivity $(\mathrm{r}=$ $0.876, \mathrm{P}=0.051$ ), which means SGLT2i with lower selectivity showed higher body weight reduction, supporting our hypothesis. Six kinds of SGLT were identified. SGLT3 was reported to function as glucose sensor rather than as glucose transporter [7]. The quantitative polymerase chain reaction analysis of
SGLT RNAs from 72 normal tissues from three different individuals showed that SGLT2 is highly kidney (cortex) specific, while SGLT5 is highly kidney (cortex and medulla) abundant; SGLT1 and SGLT4 are highly abundant in small intestine and skeletal muscle; SGLT6 is expressed in the central nervous system [8]. We analyzed the correlation of the ratio of IC50 of each SGLT2i against SGLT1 to its IC50 against SGLT2 (SGLT2 selectivity) with the ratio of IC50 of each SGLT2i against SGLT3, 4, 5, 6 to its IC50 against SGLT2, by using

Table 1. Changes in $\mathrm{HbA} 1 \mathrm{c}$ and Body Weight in Patients With Type 2 Diabetes

\begin{tabular}{|c|c|c|c|c|c|c|c|c|}
\hline \multirow{2}{*}{$\begin{array}{l}\text { SGLT2 } \\
\text { inhibitors }\end{array}$} & \multicolumn{2}{|c|}{ Changes in HbA1c (\%) } & \multicolumn{4}{|c|}{$\begin{array}{l}\text { Changes in HbA1c in patients with moder- } \\
\text { ate renal insufficiency after } 24 \text { weeks }\end{array}$} & \multicolumn{2}{|c|}{ Changes in body weight $(\mathrm{kg})$} \\
\hline & $\begin{array}{l}\text { After } 12 \\
\text { weeks }\end{array}$ & $\begin{array}{l}\text { After } 24 \\
\text { weeks }\end{array}$ & $\mathbf{n}$ & $\begin{array}{l}\text { eGFR } \\
\left(\mathrm{mL} / \mathrm{min} / 1.73 \mathrm{~m}^{2}\right)\end{array}$ & $\begin{array}{l}\text { Daily dose } \\
\text { (mg) }\end{array}$ & $\begin{array}{l}\triangle H b A 1 c \\
(\%)\end{array}$ & $\begin{array}{l}\text { After } 12 \\
\text { weeks }\end{array}$ & $\begin{array}{l}\text { After } 24 \\
\text { weeks }\end{array}$ \\
\hline \multirow[t]{2}{*}{ Dapagliflozin } & -0.37 & -0.41 & 41 & $30 \leq \mathrm{eGFR}<45$ & 5 & -0.47 & -2.06 & -2.13 \\
\hline & & & 35 & $45 \leq \mathrm{eGFR}<60$ & 5 & -0.47 & & \\
\hline Empagliflozin & -0.4 & -0.65 & 96 & $30 \leq \mathrm{eGFR}<45$ & 25 & -0.21 & -1.7 & -1.93 \\
\hline Canagliflozin & -0.8 & -0.74 & 2 & $45 \leq \mathrm{eGFR}<60$ & 100 & -0.79 & -2.53 & -2.6 \\
\hline Ipragliflozin & -0.7 & -0.87 & 58 & $30 \leq \mathrm{eGFR}<60$ & 50 & -0.28 & -1.42 & -2.38 \\
\hline Luseogliflozin & -0.39 & -0.63 & 95 & $30 \leq \mathrm{eGFR}<60$ & 2.5 & -0.11 & -1.31 & -2.7 \\
\hline Tofogliflozin & -0.77 & -1.02 & 30 & $30 \leq \mathrm{eGFR}<60$ & 20 & -0.24 & Not determined & -2.72 \\
\hline
\end{tabular}




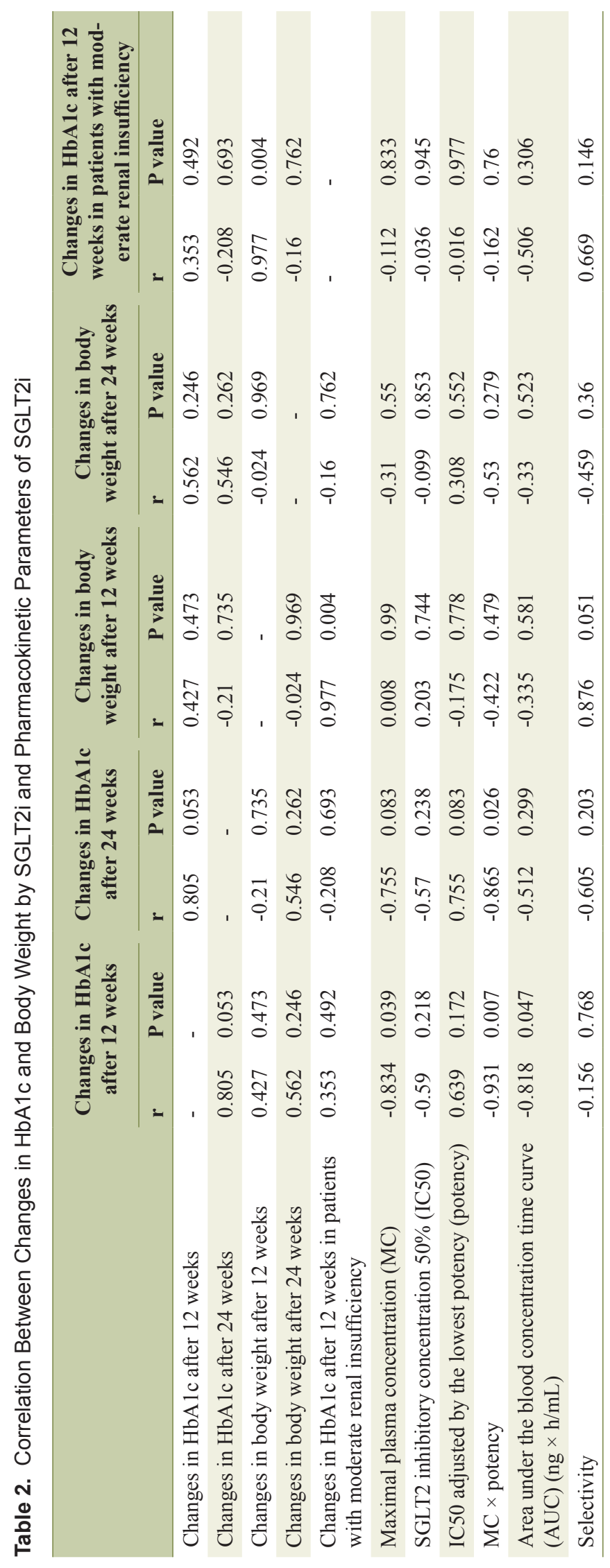

the data obtained from the article by Suzuki et al [6]. SGLT2 selectivity (IC50 (SGLT1)/IC50 (SGLT2)) was significantly correlated with (IC50 (SGLT5)/IC50 (SGLT2)) $(\mathrm{r}=0.863, \mathrm{P}=$ 0.027), and tended to be correlated with (IC50 (SGLT6)/IC50 (SGLT2) $(r=0.735, P=0.096)$. These results suggest that other organs than renal proximal tubules and/or other SGLTs than SGLT2 may be associated with body weight reduction by SGLT2i.

In conclusion, (maximum plasma concentration) $\times($ IC50 adjusted by the lowest potency) was the most crucial determinant of $\mathrm{HbA} 1 \mathrm{c}$ reduction by SGLT2i, and body weight reduction was associated with low selectivity for SGLT2.

\section{References}

1. Yanai H, Katsuyama H, Hamasaki H, Adachi H, Moriyama S, Yoshikawa R, Sako A. Sodium-Glucose Cotransporter 2 Inhibitors: Possible Anti-Atherosclerotic Effects Beyond Glucose Lowering. J Clin Med Res. 2016;8(1):1014.

2. Katsuyama H, Hamasaki H, Adachi H, Moriyama S, Kawaguchi A, Sako A, Mishima S, et al. Effects of Sodium-Glucose Cotransporter 2 Inhibitors on Metabolic Parameters in Patients With Type 2 Diabetes: A Chart-Based Analysis. J Clin Med Res. 2016;8(3):237-243.

3. Yanai H. A Significance of Sodium-Glucose Cotransporter 1 (SGLT1) Inhibition by SGLT2 Inhibitors. Int $\mathbf{J}$ Diabetes Clin Diagn. 2015;1:102.

4. Katsuyama H, Yanai H. An Influence of the Estimated Glomerular Filtration Rate on Improvement in Metabolic Parameters by Sodium-Glucose Cotransporter 2 Inhibitors. J Clin Med Res. 2016;8(6):486-488.

5. Nishiyama A, Murao K. What is Difference in SGLT2 inhibitors? -A comparison on Pharmacokinetic Properties(in Japanese). Jpn Pharmacol Ther. 2015;43(2):241-247.

6. Suzuki M, Honda K, Fukazawa M, Ozawa K, Hagita H, Kawai T, Takeda M, et al. Tofogliflozin, a potent and highly specific sodium/glucose cotransporter 2 inhibitor, improves glycemic control in diabetic rats and mice. J Pharmacol Exp Ther. 2012;341(3):692-701.

7. Mithieux G. Metabolic effects of portal vein sensing. Diabetes Obes Metab. 2014;16(Suppl 1):56-60.

8. Chen J, Williams S, Ho S, Loraine H, Hagan D, Whaley JM, Feder JN. Quantitative PCR tissue expression profiling of the human SGLT2 gene and related family members. Diabetes Ther. 2010;1(2):57-92. 